\title{
O trabalho de Conclusão de Curso (TCC) no Mestrado Profissional (MP): um estudo de caso do MP em Ciências das Religiões da Faculdade Unida (UNIDA)
}

\author{
David Mesquiati de Oliveira* \\ Julio Cezar de Paula Brotto**
}

\section{Resumo}

$\mathrm{O}$ artigo traz os resultados da pesquisa realizada junto ao Mestrado Profissional em Ciências das Religiões da Faculdade Unida de Vitória, ES (MPCR-UNIDA), e teve como objetivo avaliar o produto do referido mestrado na forma de Trabalho de Conclusão de Curso (TCC). Discorre a respeito de questões normativas relativas ao Mestrado Profissional e sobre as especificidades do Trabalho de Conclusão de Curso visto a partir da política governamental da Coordenação de Aperfeiçoamento de Pessoal de Nível Superior (CAPES, Ministério da Educação). Apresenta um histórico acerca do estabelecimento e desenvolvimento do MPCR-UNIDA, que abrange o período de 2011 a 2016. A metodologia utilizada para a análise dos dados ateve-se às seguintes categorias: crescimento quantitativo de alunos matriculados no curso, interdisciplinaridade, regionalidade das pesquisas e as temáticas dos TCC aprovados.

Palavras-chave: Atividade acadêmica. TCC. Mestrado Profissional. Estudo de caso.

Final Research Work (TCC) in The Professional Master (MP): A Case Study of the Professional Master in Sciences of Religions of The Faculdade Unida (UNIDA)

\footnotetext{
Abstract

The article presents the results of the research carried out with the Professional Master's Degree in Sciences of Religions of the Facudade Unida de Vitória, ES, Brazil (MPCR-

* Doutor em teologia (PUC-Rio), docente do Mestrado Profissional em Ciências das Religiões e da graduação em teologia na Faculdade Unida.

E-mail: david@faculdadeunida.com.br

** Doutor em Teologia Sistemático-Pastoral pela Pontifícia Universidade Católica do Rio de Janeiro. Docente do PPGCR da Faculdade Unida de Vitória, ES.

E-mail: julio.brotto@faculdadeunida.com.br
} 
-UNIDA) and had the objective of evaluating the product thesis in the form of the Final Research Work (TCC). It discusses normative issues related to the Professional Master's Degree and on the specificities of the Final Research Work (TCC) seen from the governmental policy of the Coordenação de Aperfeiçoamento de Pessoal de Nível Superior (CAPES, Brazilian Education Department). It presents a history of the establishment and development of MPCR-UNIDA, which covers the period from 2011 to 2016. The methodology used for data analysis was based on the following categories: quantitative growth of students enrolled in the course, interdisciplinarity and the themes of the approved Final Research Work (TCC).

Key-words: Academic activity. Final Research Work (TCC). Professional Master Course. Case study.

\section{Trabajo de Conclusión de Curso (TCC) enlLa Maestría Pro- fesional (MP): un estudio de caso de la Maestría en Ciencias de las Religiones de la Faculdade Unida (UNIDA)}

\section{Resumen}

El artículo presenta los resultados de la investigación llevada a cabo en la Maestría en Ciencias de las Religiones de la Faculdade Unida de Vitória, ES (Brasil), (MPCR-UNIDA), y tuvo como objetivo evaluar el producto tesis, llamado de Trabajo de Conclusión de Curso (TCC). Discute asuntos regulatorios relativos a la Maestría Profesional y los detalles específicos de la obra de conclusión a partir de la política gubernamental de la Coordenação de Aperfeiçoamento de Pessoal de Nível Superior (CAPES, Ministerio de la Educación). Presenta la historia de la creación y desarrollo de la MPCR-UNIDA, que abarca el período 2011 a 2016. La metodología utilizada para analizar los datos se ha concentrado en las siguientes categorías: crecimiento cuantitativo de estudiantes inscriptos en el curso, interdisciplinaried, regionalidad de las investigaciones y los temas de los TCC aprobados.

Palabras clave: Actividad académica. Trabajo de Conclusión de Curso (TCC). Maestría Profesional. Estudio de caso.

\section{Introdução}

Neste artigo, foram analisadas algumas questões gerais a respeito do Mestrado Profissional (MP) e sobre o Trabalho de Conclusão de Curso (TCC) a partir da política implementada pela CAPES. Para tanto, percorreu-se as Portarias desde a implantação do MP em 1995 até a mais recente publicada em 2017. A partir das Portarias, foram indicadas as especificidades do TCC no MP, visto ser esse o objeto do artigo. Os dados coletados na secretaria do Programa de Pós-Graduação em Ciências das Religiões do Mestrado Profissional da Faculdade Unida de Vitória, ES, foram fundamentais para a execução das pesquisas. O foco do artigo esteve na questão da interdiscipli- 
naridade e da regionalidade das pesquisas, bem como, a análise das temáticas dos TCC aprovados no período estudado, 2011-2016.

\section{Questões gerais sobre o MP e sobre o TCC}

\subsection{O MP e a política da CAPES}

O Mestrado Profissional (MP) é uma modalidade de curso de pós-graduação stricto sensu em nível de mestrado, diferente do Mestrado Acadêmico (MA) e conta atualmente com 771 cursos em funcionamento ${ }^{1}$ no país (CAPES, 2017). Mas qual é o específico dessa modalidade? O que se espera de um MP? Essas questões serão brevemente analisadas, tendo em vista que o objetivo deste artigo é avaliar o produto do MP na forma de Trabalho de Conclusão de Curso (TCC).

O início formal do MP deu-se na década de 1990. A Portaria nº 47 , de 1995, determinou "a implantação na Capes de procedimentos apropriados à recomendação, acompanhamento e avaliação de cursos de mestrado dirigidos à formação profissional" (CAPES, 2005, p. 147). Dos sete pontos assinalados no documento, o sétimo impôs uma característica que persiste até hoje: o autofinanciamento dos MPs: "o curso deverá procurar o autofinanciamento, devendo ser estimuladas iniciativas de convênios com vistas ao patrocínio" (CAPES, 2005, p. 148).

Renato Janine Ribeiro afirma que o argumento era de que "tratando-se de um título que agrega muito valor ao indivíduo que o obtém, bem como, à instituição ou empresa que o emprega, não é justo que os cofres das universidades públicas o financiem". E continua, "[esse financiamento] constituiria uma transferência de recursos da educação pública para outros setores, privados ou não" (RIBEIRO, 2005, p. 11). Com isso, os MPs não foram contemplados com bolsas de estudos para pesquisa das agências de fomento por meio de políticas governamentais.

Na Portaria no. 80, de 1998, a terminologia tornou-se ambígua, pois o documento usa como sinônimo o termo profissionalizante e não o atual profissional. Quanto ao termo, as críticas sinalizaram que "profissional" era mais adequado, pois a proposta dos cursos tinha como público-alvo profissionais não

De acordo com a Plataforma Sucupira, o total de cursos de pós-graduação em todas as áreas no Brasil no início de 2017 é de 6.471 cursos, somando-se todos os mestrados e doutorados. Os cursos profissionais somam 771 e os acadêmicos 5.700 . 
acadêmicos e o termo profissionalizante remontava a uma ideia de formação técnica ou de nível médio, não equiparando o MP ao MA. Além disso, o MP ficaria restrito a uma lógica produtivista. Yolanda Guerra afirma que nessa lógica o MP titularia para o mercado de trabalho, senso instrumentalizado pelo Estado e pelo Mercado. No caso do Estado, alcançando a meta do país para o aumento do número de titulados. Para o Mercado, "em razão da sua natureza, formato e objetivos [do MP], a pesquisa inovadora e autônoma desaparece. A educação se realiza cada vez mais conectada com a lógica do mercado, como um bem de consumo imediato". E conclui: "Neste formato, há o interesse no aproveitamento de mestres nos setores produtivos e de doutores na pesquisa" (GUERRA, 2013, p. 2). Janine Ribeiro pondera que é preciso conjugar dois interesses nessa questão do MP, o desenvolvimento econômico e o desenvolvimento social, e aqui estaria a importância do MP, sua contribuição no resgate da dívida social, especialmente na gestão da Saúde e da Educação, em que o conhecimento mais qualificado seria aplicado socialmente (RIBEIRO, 2005, p. 13).

Com a Portaria Normativa 17, de 28 de dezembro de 2009, o MEC objetivou regulamentar o MP no âmbito da CAPES. Esse documento direcionou o MP para "desenvolver atividades e trabalhos técnico-científicos em temas de interesse público". Em seu artigo $3^{\circ}$., a modalidade MP é definida em termos de capacitação para a "prática profissional avançada e transformadora de procedimentos e processos aplicados" e "incorporação e atualização permanentes dos avanços da ciência e das tecnologias [...] para a solução de problemas específicos". Nos artigos $4^{\circ}$. e $5^{\circ}$., os termos "procedimentos", "transferir conhecimento para a sociedade", "aumentar a produtividade", "prática do ensino" e "pesquisa aplicada" marcam seu teor. $\mathrm{O}$ artigo $7^{\circ}$. estabelece:

A proposta de Mestrado Profissional deverá, necessária e obrigatoriamente: I - apresentar estrutura curricular objetiva, coerente com as finalidades do curso e consistentemente vinculada à sua especificidade, enfatizando a articulação entre conhecimento atualizado, domínio da metodologia pertinente e aplicação orientada para o campo de atuação profissional.

II - possibilitar a inclusão, quando justificável, de atividades curriculares estruturadas das áreas das ciências sociais aplicadas correlatas com o curso, tais como legislação, comunicação, administração e gestão, ciência política e ética (MEC, 2009, p. 21). 
O trabalho de Conclusão de Curso (TCC) no Mestrado Profissional (MP): um estudo de 195 caso do MP em Ciências das Religiões da Faculdade Unida (UNIDA)

Muito recentemente, em 24 de março de 2017, foi publicada no Diário Oficial da União (DOU), a Portaria $\mathrm{n}^{\circ} .389$, que, entre outras coisas, instituiu o inédito Doutorado Profissional (DP). Esse passo indica que a política com o MP está alcançando seus objetivos e que o DP seria o passo seguinte na consolidação dessa política pública. Caso contrário, o esforço por formar um profissional de alto nível sofreria retração com esses profissionais migrando para a área acadêmica (Doutorado Acadêmico, DA). Contudo, o problema se instaura quando o texto da Portaria $\mathrm{n}^{\circ} .389$, em seu artigo $5^{\circ}$., estabelece que “fica revogada a Portaria no. 17, de 28 de dezembro de 2009". Na Portaria 17 estavam disciplinados vários elementos do MP. De acordo com o artigo $4^{\circ}$. da mesma portaria, a "Capes terá o prazo de 180 dias para regulamentar e disciplinar, por meio de portaria, a oferta, a avaliação e o acompanhamento dos programas de mestrado e doutorado profissional" (MEC, 2017, p. 61). Com a Portaria 17 revogada e esse prazo de 180 dias para se regulamentar e disciplinar o MP, ficou-se em um vácuo jurídico. As ações que envolvem DPs terão que aguardar a nova portaria, sem muitas consequências, mas os MPs em funcionamento ficam juridicamente descobertos nesse período. Isto é, a nova portaria pode simplesmente ratificar o que estava regulamentado na anterior, o que seria simples, mas por sua vez, também pode estabelecer novas exigências e novos enfoques para os MPs atuais. De qualquer forma, os MPs em funcionamento se guiarão em termos práticos ainda pela Portaria Normativa $17 / 09$, até que se publique uma nova portaria.

O texto da Portaria 389 de 2017 traz redação semelhante à Portaria 17/09. Por se tratar de uma peça concisa, reproduzimos seu teor:

\section{CONSIDERANDO:}

As disposições da Lei no 9.394 de 20 de dezembro de 1996; e A relevância social, científica e tecnológica dos processos de formação profissional avançada, bem como o necessário estreitamento das relações entre as universidades e o setor produtivo, resolve:

Art. $1^{\circ}$ Fica instituída, no âmbito da pós-graduação stricto sensu, a modalidade de mestrado e doutorado profissional.

Art. $2^{\circ}$ São objetivos do mestrado e doutorado profissional:

I - capacitar profissionais qualificados para o exercício da prática profissional avançada e transformadora de procedimentos, visando atender demandas sociais, organizacionais ou profissionais e do mercado de trabalho;

II - transferir conhecimento para a sociedade, atendendo demandas específicas e de arranjos produtivos com vistas ao desenvolvimento nacional, regional ou local; 
III - promover a articulação integrada da formação profissional com entidades demandantes de naturezas diversas, visando melhorar a eficácia e a eficiência das organizações públicas e privadas por meio da solução de problemas e geração e aplicação de processos de inovação apropriados; e

IV - contribuir para agregar competitividade e aumentar a produtividade em empresas, organizações públicas e privadas.

Art. $3^{\circ}$ Os títulos de mestres e doutores obtidos nos cursos profissionais avaliados pela Coordenação de Aperfeiçoamento de Pessoal de Nível Superior - Capes, reconhecidos pelo Conselho Nacional de Educação - CNE e homologados pelo Ministro de Estado da Educação, terão validade nacional (MEC, 2017, p. 61).

As políticas da CAPES para os programas de pós-graduação stricto sensu profissionais são no sentido de enfatizar que o MP, e agora o DP, têm vocação direta para o desenvolvimento econômico e social do país, por meio de uma consistente transferência de conhecimentos da academia para a sociedade. Com isso, não só promoveria avanços nos indicadores sociais, contribuindo para sanar o déficit nas áreas de saúde e educação - sem prejuízo para outras áreas -, mas também ampliaria as possibilidades de aplicação pessoal e profissional das pesquisas acadêmicas.

\subsection{As especificidades do TCC no MP}

Considerando a Portaria normativa $n^{\circ}$. 17, de 2009, o TCC do MP tem as seguintes características:

O trabalho de conclusão final do curso poderá ser apresentado em diferentes formatos, tais como dissertação, revisão sistemática e aprofundada da literatura, artigo, patente, registros de propriedade intelectual, projetos técnicos, publicações tecnológicas; desenvolvimento de aplicativos, de materiais didáticos e instrucionais e de produtos, processos e técnicas; produção de programas de mídia, editoria, composições, concertos, relatórios finais de pesquisa, softwares, estudos de caso, relatório técnico com regras de sigilo, manual de operação técnica, protocolo experimental ou de aplicação em serviços, proposta de intervenção em procedimentos clínicos ou de serviço pertinente, projeto de aplicação ou adequação tecnológica, protótipos para desenvolvimento ou produção de instrumentos, equipamentos e kits, projetos de inovação tecnológica, produção artística, sem prejuízo de outros formatos, de acordo com a natureza da área e a finalidade do curso, desde que previamente propostos e aprovados pela CAPES (MEC, 2009, p. 21). 

caso do MP em Ciências das Religiões da Faculdade Unida (UNIDA)

Marco Moreira e Roberto Nardi observam que "ainda que se mantenha a nomenclatura de dissertação, a natureza do trabalho de conclusão do mestrado profissional é distinta da do acadêmico". E continua: "trata-se do relato de uma experiência de implementação de estratégias ou produtos de natureza educacional, visando à melhoria do ensino em uma área específica". Isto é, a dissertação é "sobre esse produto, sobre sua geração e implementação, mas ao mesmo tempo, deve ter identidade própria”. Mais adiante, eles concluem: “não se trata de dizer que 'está na dissertação'; esse produto é considerado como produção técnica indispensável para a conclusão do mestrado profissional" (MOREIRA; NARDI, 2009, p. 4).

No entanto, Quaresma e Machado afirmam:

...embora se falem em outras possibilidades de trabalho de conclusão no mestrado profissional de modo a atender necessidades postas em forma de problema no início do curso e de intervenção na prática profissional, a dissertação seria o veículo indicado para expor o resultado final do trabalho de pesquisa e desenvolvimento e ela é compreendida como o suporte adequado para viabilizar a finalidade do mestrado profissional de promover a integração da formação do aluno com sua experiência social (QUARESMA; MACHADO, 2014, p. 475).

Mais adiante, as referidas autoras vão afirmar também:

Em quaisquer das modalidades expostas, como produto final no mestrado profissional, a dissertação teria, necessariamente, a característica de ser iniciada com base em um fato ou ação inquietante, em um problema concreto, e não em uma questão teórica, caminho que seria apropriado aos mestrados acadêmicos (QUARESMA; MACHADO, 2014, p. 475).

Caberia nesse momento reformar a diferença entre o MA e o MP. Recorremos uma vez mais a Janine Ribeiro, que esclarece da seguinte forma: "a principal diferença entre o MA e o MP é o produto, isto é, o resultado almejado". E continua:

No MA, pretende-se pela imersão na pesquisa formar, a longo prazo, um pesquisador. No MP, também deve ocorrer a imersão na pesquisa, mas o objetivo é formar alguém que, no mundo profissional externo à academia, saiba localizar, reconhecer, identificar e, sobretudo, utilizar a pesquisa de modo a agregar valor a suas atividades, sejam essas de interesse mais pessoal ou mais social. Com tais características, o MP aponta para uma clara diferença no 
perfil do candidato a esse mestrado e do candidato ao mestrado acadêmico (RIBEIRO, 2005, p. 15).

Assim, de acordo com as portarias que lhe deram forma e segundo os investigadores que pesquisam o tema, os TCC no MP preferencialmente deveriam constituir-se de "casos de aplicação do conhecimento científico ao ambiente profissional para o qual se volta o MP” (RIBEIRO, 2005, p. 15), sendo seu diferencial "a ênfase na adição de valor social ao mercado de trabalho e à comunidade em geral, focando a profissionalização e gestão das mais diversas formas de atividades sociais, empresariais, tecnológicas e até culturais" (SILVEIRA; PINTO, 2005, p. 39). Contudo, reitera-se que a portaria que disciplinava os MPs foi revogada no dia 24 de março de 2017 e se aguarda nova portaria, que poderá introduzir novos elementos.

\section{O MP em Ciências das Religiões da Faculdade Unida ${ }^{2}$ (MPCR-UNIDA)}

\subsection{Dados gerais do MPCR-UNIDA}

O MPCR-UNIDA foi autorizado pela CAPES, em 2010, por meio do Parecer CNE/CES n. 168/2011 (MEC, 2011, p. 40) e posteriormente homologado pela Portaria 1.364, de 29 de setembro de 2011. O curso está organizado em regime modular com encontros intensivos em cada janeiro e julho consecutivos em um período de 24 meses para integralização dos créditos e defesa do Trabalho de Conclusão de Curso (TCC). A primeira turma começou em janeiro de 2011. O período para a análise deste artigo compreende de 2011 a 2016.

2 A Faculdade Unida de Vitória (UNIDA) foi credenciada pela Portaria do MEC nº. 3.914, de 14 de novembro de 2005, publicada no D.O.U. de 16 de novembro de 2005 e recredenciada pela Portaria do MEC n. 918, de 17 de agosto de 2016 - DOU de 18/08/2016. A Faculdade Unida de Vitória é uma IES autônoma. Não possui vínculo de dependência institucional com qualquer instituição, salvo sua mantenedora, Centro de Estudos Especializados, que, todavia, por sua vez, não tem qualquer relação formal de dependência político-ideológica, fiscal, econômico-financeira ou teológico-religiosa com qualquer organismo, agência ou instituição. Sua manutenção financeiro-fiscal deve-se exclusivamente aos cursos que mantém: Graduação em Teologia, na modalidade presencial, Graduação em Teologia, na modalidade a distância, bem como, convalidação em Teologia e cursos livres de Teologia, além de cursos de pós-graduação lato sensu, na modalidade presencial, e pós-graduação lato-sensu, na modalidade a distância, cursos de extensão e, finalmente, pós-graduação stricto sensu, especificamente, o Mestrado Profissional em Ciências das Religiões. 
De acordo com o sítio web do MPCR-UNIDA, os objetivos do curso são:

(a) a compreensão das relações entre as religiões e a sociedade democrática nas suas diversas dimensões, com ênfase no incremento crítico da participação religiosa na vida social; e (b) a análise dos discursos religiosos canônicos e não canônicos, com vistas à compreensão crítica dos modos de produção, interpretação, circulação e difusão do discurso religioso no âmbito sociocultural. Nesse campo, conquanto não exclusivamente, há ênfase nos cristianismos originários e históricos, acentuando-se análises dos discursos por meio de ferramentas tanto semióticas quanto exegéticas histórico-críticas (UNIDA, 2017).

A metodologia utilizada para a análise dos dados ateve-se às seguintes categorias: crescimento quantitativo de alunos matriculados no curso, interdisciplinaridade, regionalidade das pesquisas e as temáticas dos TCC aprovados. Os dados foram coletados na secretaria do Programa de Pós-Graduação em Ciências das Religiões, Mestrado Profissional, da Faculdade Unida de Vitória, entre dezembro de 2016 até março de 2017.

A Figura 1 consolida os dados ano a ano das 12 turmas abertas no período de forma consecutiva a cada semestre no referido MP:

Figura 1 - Distribuição dos alunos do MPCR-UNIDA 2011-2016

\begin{tabular}{|l|c|c|c|c|c|c|c|}
\hline \multicolumn{1}{|c}{ MATRÍCULAS } & $\mathbf{2 0 1 1}$ & $\mathbf{2 0 1 2}$ & $\mathbf{2 0 1 3}$ & $\mathbf{2 0 1 4}$ & $\mathbf{2 0 1 5}$ & $\mathbf{2 0 1 6}$ & Total \\
\hline Início do curso & 38 & 42 & 53 & 56 & 68 & 79 & 336 \\
\hline Trancados & 0 & 0 & 0 & 3 & 6 & $7 *$ & 16 \\
\hline Canceladas & 0 & 0 & 2 & 2 & 6 & 5 & 15 \\
\hline $\begin{array}{l}\text { Abandono/jubilado por } \\
\text { turma/ano }\end{array}$ & 10 & 3 & 7 & 16 & 9 & 1 & $46^{* *}$ \\
\hline $\begin{array}{l}\text { Concluído por turma/ ano } \\
\text { Reprovados, referente à }\end{array}$ & 28 & 38 & 41 & 31 & 13 & $0 * * *$ & 151 \\
\hline \begin{tabular}{l} 
turma/ano \\
\hline
\end{tabular} & & & 3 & & & & 3 \\
\hline
\end{tabular}

Fonte: Dados organizados pelos autores a partir de documentação da secretaria do MPCR-UNIDA.

* Inclui um trancamento que foi efetivado em janeiro de 2017 referente à turma ativa no período analisado.

** Inclui quatro abandonos/jubilamentos que foram efetivados em janeiro de 2017 referentes às turmas ativas no período analisado.

*** As turmas iniciadas em 2016 ainda estão em fase de integralização dos créditos, portanto, sem TCC ainda. 
Chama a atenção o número crescente de ingressantes no MP ano a ano, com taxa básica de crescimento de 15,76\% ao ano. ${ }^{3} \mathrm{Na}$ Figura 2 é possível visualizar melhor esse crescimento:

Figura 2 - Crescimento do número de matrículas ano a ano

\section{Matriculados}

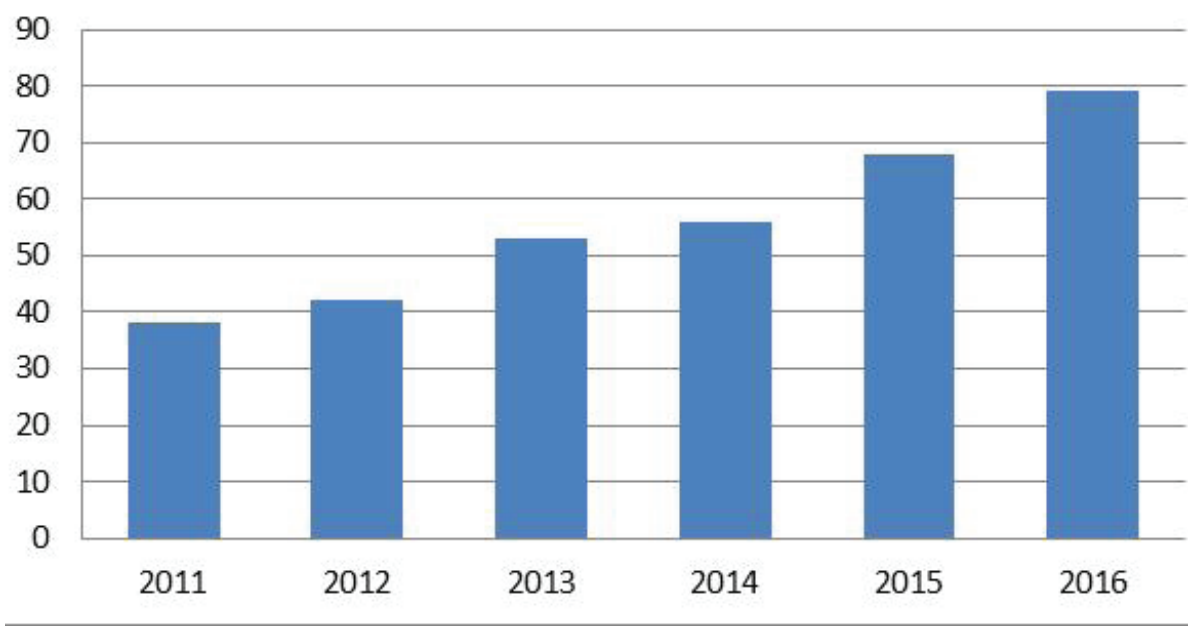

Fonte: Dados organizados pelos autores, a partir de documentação da secretaria do MPCR-UNIDA.

Mas o item que de fato nos interessa neste artigo é o produto final dos que concluíram o curso, o TCC. De acordo com a Figura 1, foram 151 TCC aprovados entre 2011 e 2016. A visão dessa figura é a conclusão de TCC por turma. Na Figura 3, faremos uma nova série com as aprovações registradas ano a ano. É preciso considerar que, em 2011, não houve bancas para a avaliação, tendo em vista que os estudantes não concluíram a integralização dos créditos.

3 A taxa básica (TB) ou média anual foi calculada considerando as informações da Tabela 1 e por meio da fórmula $\mathrm{TB}=(\text { presente } / \text { passado })^{1 / \mathrm{n}}-1$, em que presente é o número de matriculados de 2016, passado o número de matriculados de 2011 e $n$ a quantidade de anos da série. 
O trabalho de Conclusão de Curso (TCC) no Mestrado Profissional (MP): um estudo de 201 caso do MP em Ciências das Religiões da Faculdade Unida (UNIDA)

Figura 3 - TCC aprovados ano a ano (2011-2016)

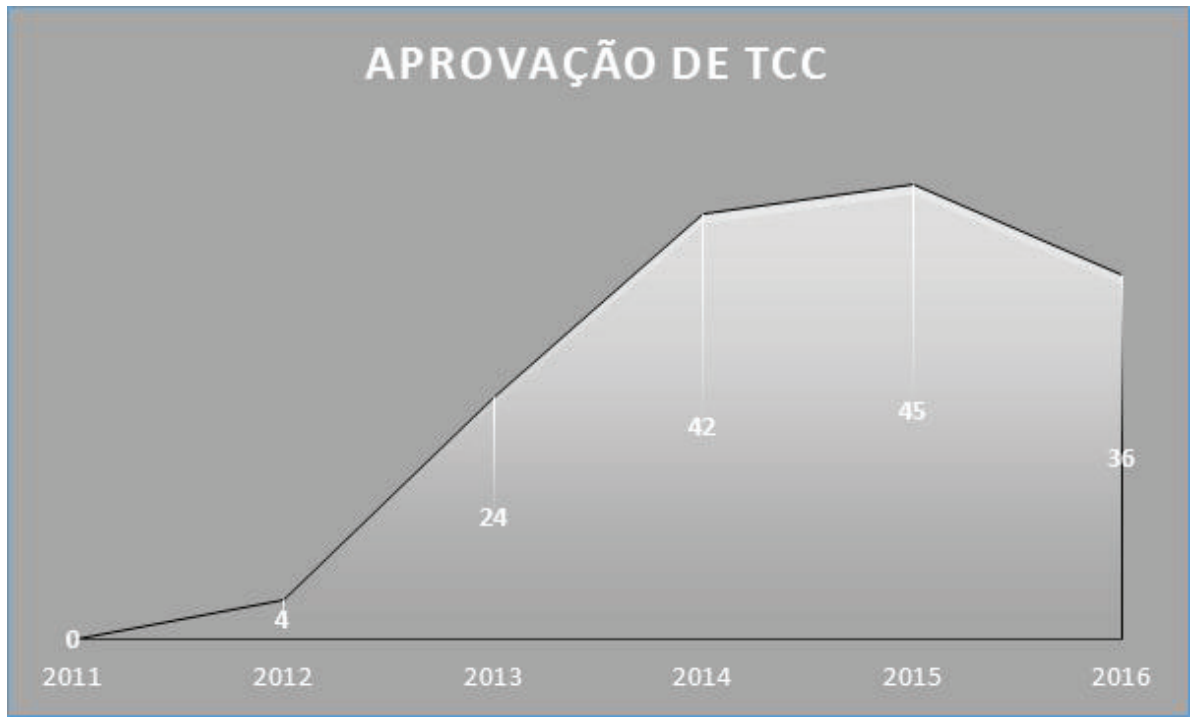

Fonte: Dados organizados pelos autores, a partir de documentação da secretaria do MPCR-UNIDA.

A sensível queda no total de defesas no ano de 2016 (apenas 36, comparada com 45 do ano anterior) merece atenção. Em primeiro lugar, esse desempenho depende das turmas de 2015, que apesar de terem crescido em número de matriculados, tiveram mais baixas que anos anteriores (trancamentos, cancelamentos e abandono). Em segundo lugar, os ingressantes no segundo período de 2015 ainda não cumpriram os 24 meses, estando dentro do prazo para apresentar o TCC no primeiro semestre de 2017. Em terceiro lugar, os pedidos de prorrogação de prazo, que podem estender o prazo para a defesa do TCC em até seis meses ao mestrando, impactando o número final do ano. Com tudo isso, considerando os anos de efetiva possibilidade de aprovação (a partir de 2012) e o total de 151 aprovações, a média de TCC aprovados por ano nesse MP é de 30,2 TCC por ano.

\subsection{Análise da interdisciplinaridade do TCC no MPCR-UNIDA}

A nova área da árvore do conhecimento da CAPES, na qual o MPCR-UNIDA está inserido, é Teologia, que na plataforma Sucupira, aparece como Teologia e Ciência da Religião, trabalha em permanente diálogo com outras áreas do saber. O MP, enquanto modalidade de pós-graduação stricto sensu, 
também possui um caráter interdisciplinar. Renato Janine Ribeiro afirma que "o MP tem com frequência uma natureza interdisciplinar" (RIBEIRO, 2005, p. 12). Assim, é de se esperar que os TCC apresentem aproximações ao objeto de pesquisa de forma interdisciplinar.

Considerando as oito áreas do conhecimento definidas pelo CNPq e analisando os títulos dos 151 TCC apresentados no período escolhido, foi possível elaborar a Figura 4:

Figura 4 - Distribuição dos TCC por área de conhecimento e por ano (2011-2016)

\begin{tabular}{lcc}
\multicolumn{1}{c}{ ÁREAS DO CONHECIMENTO DO CNPq } & $\mathbf{N}^{\mathbf{0}}$ & \% do total \\
\hline Ciências Humanas & 111 & 73,5 \\
\hline Ciências Sociais Aplicadas & 30 & 19,9 \\
\hline Ciências de Saúde & 5 & 3,3 \\
\hline Linguística, letras e artes & 5 & 3,3 \\
\hline Ciências Agrárias & 0 & 0,0 \\
\hline Engenharias & 0 & 0,0 \\
\hline Ciências Biológicas & 0 & 0,0 \\
\hline Ciências exatas e da terra $\quad$ TOTAL & 0 & 0,0 \\
\hline \multicolumn{1}{c}{$\quad \mathbf{1 5 1}$} & $\mathbf{1 0 0}$ \\
\hline
\end{tabular}

Fonte: Dados organizados pelos autores a partir dos títulos, palavras-chave e resumos dos TCC.

Percebe-se que não houve pesquisas com interface nas áreas das Ciências Agrárias, Engenharias, Ciências Biológicas e Ciências Exatas e da Terra. As pesquisas, ao contrário, se concentraram na área em que o MP está inserido, as Ciências Humanas, com 73,5\% dos TCC, seguido da área Ciências Sociais Aplicadas com 19,9\% e das Ciências da Saúde e da Linguística, Letras e Artes, ambas as áreas com 3,3\% respectivamente (5 TCC do total de 151 para cada área no período). Buscando analisar as áreas específicas ou subáreas que os TCC se relacionavam, criou-se as Figuras 5 a 8 . Nelas os TCC são distribuídos de acordo com a disciplina que mais dialogou, mas pode haver sobreposição de disciplinas acadêmicas, o que não aparece nessas figuras. 
O trabalho de Conclusão de Curso (TCC) no Mestrado Profissional (MP): um estudo de 203 caso do MP em Ciências das Religiões da Faculdade Unida (UNIDA)

Figura 5 - Distribuição dos TCC 2011-2016 na Área de Ciências Humanas

\begin{tabular}{lccc}
\multicolumn{1}{c}{ CIÊNCIAS HUMANAS } & $\mathbf{N}^{\mathbf{0}}$ & \% da área & \% do total \\
\hline Antropologia & 4 & 3,6 & 2,6 \\
\hline Ciências Políticas & 1 & 0,9 & 0,7 \\
\hline Educação & 55 & 49,5 & 36,4 \\
\hline Filosofia & 8 & 7,2 & 5,3 \\
\hline Geografia & 4 & 3,6 & 2,6 \\
\hline História & 5 & 4,5 & 3,3 \\
\hline Psicologia & 8 & 7,2 & 5,3 \\
\hline Sociologia & 19 & 17,1 & 12,6 \\
\hline Teologia & 7 & 6,3 & 4,6 \\
\hline & $\mathbf{1 1 1}$ & $\mathbf{1 0 0}$ & $\mathbf{7 3 , 5}$
\end{tabular}

Fonte: Dados organizados pelos autores a partir dos títulos, palavras-chave e resumos dos TCC.

Nota-se que a maioria dos TCC esteve na área da Educação (55 TCC), seguido da sociologia, especialmente a sociologia da religião (19 TCC). Mas ocorreram pesquisas na interface com Antropologia (4), especialmente questões indígenas e de negritude, Ciências Políticas (1), Filosofia (8), Geografia (4), História (5), Psicologia (8) e Teologia (7). A maioria das pesquisas versa sobre o cristianismo e sua influência na sociedade brasileira, mas há também pesquisas acerca de religiões afro-brasileiras como a Umbanda (1), sobre religiões africanas (2), religiões indígenas (4), a respeito de religião e currículo das escolas (5) e sobre violência contra a mulher (1).

Figura 6 - Distribuição dos TCC 2011-2016 na Área Ciências Sociais Aplicadas

\begin{tabular}{lccc} 
CIÊNCIAS SOCIAIS APLICADAS & $\mathbf{N}^{\mathbf{0}}$ & $\begin{array}{c}\text { \% da } \\
\text { área }\end{array}$ & \% do total \\
\hline Administração & 3 & 10,0 & 2,0 \\
\hline Comunicação Social & 4 & 13,3 & 2,6 \\
\hline Direito & 14 & 46,7 & 9,3 \\
\hline Economia & 2 & 6,7 & 1,3 \\
\hline Serviço Social & 7 & 23,3 & 4,6 \\
\hline \multicolumn{1}{c}{ TOTAL } & $\mathbf{3 0}$ & $\mathbf{1 0 0}$ & $\mathbf{1 9 , 9}$
\end{tabular}

Fonte: Dados organizados pelos autores a partir dos títulos, palavras-chave e resumos dos TCC.

$\mathrm{Na}$ área das Ciências Sociais, o referido MP produziu TCC em diálogo com cinco subáreas do conhecimento, sendo a maioria na interface com o Direito (14), com o Serviço Social (7), Comunicação Social (4), Administração (3) e Economia (2). Os temas no campo da Administração giraram em 
torno da espiritualidade e da religiosidade em ambientes corporativos, sua influência e possibilidades de melhor aproveitamento para a sociedade. $\mathrm{Na}$ Comunicação, o foco esteve na análise dos discursos religiosos nas mídias eletrônicas, tanto o discurso neopentecostal midiático como o discurso católico televisivo e nas redes sociais. Na questão da Economia, pesquisou-se a influência da religião nas questões mercadológicas, tanto nacional como no mercado internacional, como foi o caso de um TCC que analisou a questão da religião no mercado indiano. Na área do Direito, os TCC versaram acerca de temas e enfoques variados, gerando subsídios para o debate sobre o Ensino Religioso, para a questão da laicidade do Estado, entre outros. Por último, na área do Serviço Social, os temas giraram em torno da ressocialização de detentos no sistema prisional e fora dele, a questão da dependência química e de entorpecentes, além de questões envolvendo o assistencialismo e metodologias de participação cidadã.

Figura 7 - Distribuição dos TCC 2011-2016 na Área Ciências da Saúde

\begin{tabular}{|c|c|c|c|}
\hline CIÊNCIAS DA SAÚDE & $\mathbf{N}^{\mathbf{0}}$ & \% da área & $\%$ do total \\
\hline Enfermagem & 4 & 80,0 & 2,6 \\
\hline Psiquiatria & 1 & 20,0 & 0,7 \\
\hline TOTAL & 5 & 100 & 3,3 \\
\hline
\end{tabular}

Fonte: Dados organizados pelos autores a partir dos títulos, palavras-chave e resumos dos TCC.

Na área da Ciência da Saúde, os TCC se concentraram na interface com a Enfermagem (4) e com a Psiquiatria (1). Quanto ao último, no entanto, outras duas pesquisas igualmente abordaram temas de saúde mental, mas foram classificadas em outra área, uma vez que o título da pesquisa fazia menção direta a elas. Dessa forma, tratando especificamente da questão da saúde mental, então, forma 3 TCC no período.

Figura 8 - Distribuição dos TCC 2011-2016 na Área da Linguística, Letras e Artes

\begin{tabular}{lcccc}
\hline \multicolumn{2}{c}{ LINGUISTICA, LETRAS E } & No & \% da área & \% do total \\
\hline Letras & & 2 & 40,0 & 1,3 \\
\hline Linguística & TOTAL & 3 & 60,0 & 2,0 \\
\hline
\end{tabular}

Fonte: Dados organizados pelos autores a partir dos títulos, palavras-chave e resumos dos TCC. 
O trabalho de Conclusão de Curso (TCC) no Mestrado Profissional (MP): um estudo de 205 caso do MP em Ciências das Religiões da Faculdade Unida (UNIDA)

Na área de Linguística, Letras e Artes os TCC se concentraram na questão linguística, com três TCC dissertando a partir das escolas francesas da análise do discurso e sua aplicabilidade no contexto brasileiro e outras duas pesquisas sobre questões envolvendo especificamente estudos literários. Da mesma forma que na questão anterior, há outros TCC que trataram acerca da análise do discurso e sobre estudos literários, mas que foram classificados em interface com outras áreas mais explícitas no título do TCC.

Figura 9 - Principais temáticas dos TCC 2011-2016

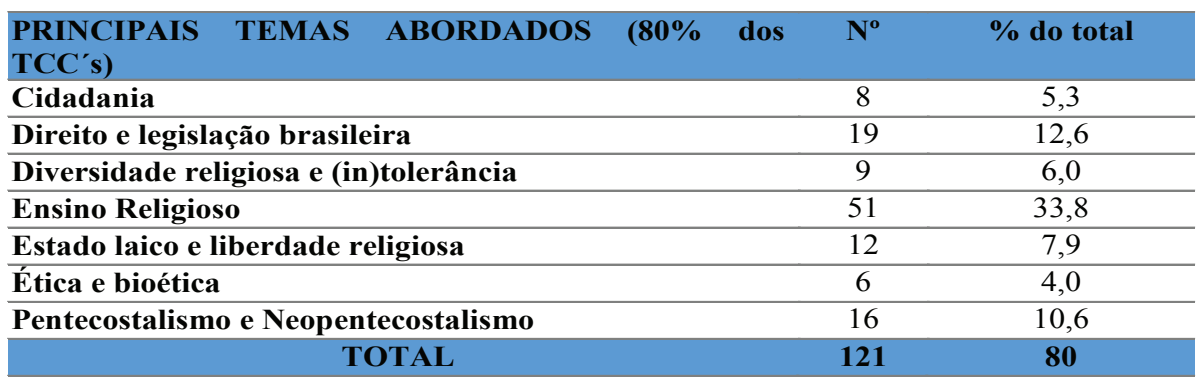

Fonte: Dados organizados pelos autores a partir dos títulos, palavras-chave e resumos dos TCC.

A Figura 9, por sua vez, explicita os principais temas abordados nos TCC do MPCR-UNIDA no período 2011-2016. A questão do Ensino Religioso foi a mais pesquisada, com 51 TCC (33,8\% do total dos TCC). Em segundo lugar, esteve a temática da legislação brasileira e questões do Direito (19 TCC, 12,6\% da produção). Em terceiro lugar, o tema do pentecostalismo (e do neopentecostalismo) em suas variações de análise do discurso, uso das mídias eletrônicas, comércio do sagrado, entre outros. Em quarto lugar, retomam-se algumas questões jurídicas específicas, como a noção de Estado Laico e a questão da liberdade religiosa (12 TCC, 7,9\%). Em quinto lugar, esteve o debate sobre a diversidade religiosa e a tolerância e intolerância religiosa (9 TCC, 6\%). Em sexto lugar, temas sobre cidadania e participação social (8 TCC, 5,3\%) e, em sétimo lugar (6 TCC, 4\% do total), questões práticas envolvendo temas da ética e da ética aplicada (bioética), como aborto, eutanásia, transfusão de sangue e guarda do sábado, por exemplo. Esses temas ocuparam 80\% dos TCC aprovados no período de 2011 a 2016. 


\subsection{Análise da regionalidade dos objetos de pesquisa dos TCC}

O objetivo específico aqui é descrever as cidades, Estados e regiões brasileiras que foram objeto de pesquisa nos TCC aprovados no período em estudo. Esses dados podem dar a dimensão do alcance regional do referido MP, em sua proposta em atender não só a região na qual está inserido, mas também de ser uma alternativa para outras regiões do país na oferta de cursos de pós-graduação strictu senso. A Figura 10 consolida os dados em sua visão macro:

Figura 10 - Quanto à localização geográfica específica na abordagem temática dos TCC

\begin{tabular}{lcc} 
REGIONALIDADE & $\mathrm{N}^{\circ}$ & $\begin{array}{c}\% \text { do } \\
\text { total }\end{array}$ \\
\hline Municipal & 38 & 25,2 \\
\hline Estadual & 14 & 9,3 \\
\hline Regional & 3 & 2,0 \\
\hline Nacional & 96 & 63,6 \\
\hline \multicolumn{1}{c}{ TOTAL } & 151 & 100 \\
\hline
\end{tabular}

Fonte: Dados organizados pelos autores a partir dos títulos, palavras-chave e resumos dos TCC.

Os dados mostram que 96 dos 151 TCC aprovados no período, isto é, $63,6 \%$ das pesquisas, fizeram abordagens nacionais do fenômeno investigado no Brasil. Isso mostra um grau elevado de abordagens genéricas, fruto da metodologia aplicada, que tende a ser a revisão bibliográfica e abordagens panorâmicas, ${ }^{4}$ no dizer de Umberto Eco (2005), ou de dissertações interpretativas, de P. Mattos (1997). Houve 3 TCC que se concentraram em uma abordagem regional, sendo um o mapeamento da região Centro-Oeste, outro o da Nordeste e o terceiro o da região Norte, cada qual a partir do seu respectivo fenômeno. Contudo, é expressiva a quantidade de pesquisas em cidades específicas $(25,2 \%$ da produção), distribuídas em quatro das cinco regiões brasileiras. Esse alcance é algo muito positivo, pois pode indicar uma maior proximidade do estudo dos fenômenos em casos concretos. As

\footnotetext{
4 Panorâmicas no sentido usado por Umberto Eco, em que os temas escolhidos são amplos e de caráter descritivo (Cf. ECO, 2005). Mattos (1997), por sua vez, classifica as dissertações em interpretativas, projetivas e avaliativas, em que as interpretativas seriam aquelas que se ocupam com a explicação de fatos ou situações (Cf. MATTOS, 1997, p. 168s.).
} 
O trabalho de Conclusão de Curso (TCC) no Mestrado Profissional (MP): um estudo de 207 caso do MP em Ciências das Religiões da Faculdade Unida (UNIDA)

Figuras 11 e 12 apresentam os dados abertos em relação aos itens "Municipal" e "Estadual".

Figura 11 - Quanto às cidades objetos de pesquisa nos TCC

\begin{tabular}{lccccc} 
Pesquisas nas Cidades & $\mathbf{N}^{\mathbf{0}}$ & $\begin{array}{c}\text { \% das } \\
\text { Municipais }\end{array}$ & $\begin{array}{c}\text { \% do } \\
\text { total }\end{array}$ & Estado & Região \\
\hline Aracruz-ES & 1 & 2,6 & 0,7 & Espírito Santo & Sudeste \\
\hline Campos-RJ & 1 & 2,6 & 0,7 & Rio de Janeiro & Sudeste \\
\hline Cárceres-MT & 1 & 2,6 & 0,7 & Mato Grosso & Centro-Oeste \\
\hline Cariacica-ES & 2 & 5,3 & 1,3 & Espírito Santo & Sudeste \\
\hline Colatina-ES & 4 & 10,5 & 2,6 & Espírito Santo & Sudeste \\
\hline Itabela-BA & 1 & 2,6 & 0,7 & Bahia & Nordeste \\
\hline Itaperuna-RJ & 1 & 2,6 & 0,7 & Rio de Janeiro & Sudeste \\
\hline Juazeiro do Norte-CE & 1 & 2,6 & 0,7 & Ceará & Nordeste \\
\hline Macaé-RJ & 1 & 2,6 & 0,7 & Rio de Janeiro & Sudeste \\
\hline Macapá-AP & 1 & 2,6 & 0,7 & Amapá & Norte \\
\hline Montes Claros-MG & 1 & 2,6 & 0,7 & Minas Gerais & Sudeste \\
\hline Nanuque-MG & 1 & 2,6 & 0,7 & Minas Gerais & Sudeste \\
\hline Porto Seguro-BA & 1 & 2,6 & 0,7 & Bahia & Nordeste \\
\hline Porto Velho-RO & 1 & 2,6 & 0,7 & Rondônia & Norte \\
\hline Recanto Italva-RJ & 1 & 2,6 & 0,7 & Rio de Janeiro & Sudeste \\
\hline Santa Teresa-ES & 1 & 2,6 & 0,7 & Espírito Santo & Sudeste \\
\hline Santarém-PA & 1 & 2,6 & 0,7 & Pará & Norte \\
\hline São Gonçalo-RJ & 1 & 2,6 & 0,7 & Rio de Janeiro & Sudeste \\
\hline São Paulo-SP & 1 & 2,6 & 0,7 & São Paulo & Sudeste \\
\hline Serra-ES & 3 & 7,9 & 2,0 & Espírito Santo & Sudeste \\
\hline Teófilo Otoni-MG & 1 & 2,6 & 0,7 & Minas Gerais & Sudeste \\
\hline Sahu-Apé-AM & 1 & 2,6 & 0,7 & Amazonas & Norte \\
\hline Uru Eu Wau Wau-RO & 1 & 2,6 & 0,7 & Rondônia & Norte \\
\hline Vila Velha-ES & 4 & 10,5 & 2,6 & Espírito Santo & Sudeste \\
\hline Vitória-ES & 5 & 13,2 & 3,3 & Espírito Santo & Sudeste \\
\hline & $\mathbf{3 8}$ & $\mathbf{1 0 0}$ & $\mathbf{2 5 , 2}$ & $\mathbf{1 1}$ & $\mathbf{4}$ \\
\hline
\end{tabular}

Fonte: Dados organizados pelos autores a partir dos títulos, palavras-chave e resumos dos TCC.

Observa-se que os 38 TCC aprovados que enfocaram casos específicos em cidades, analisaram 25 cidades do país, situadas em 11 Estados diferentes (AM, AP, BA, CE, ES, MG, MT, PA, RJ, RO e SP) e em quatro regiões brasileiras, a saber, Sudeste, Nordeste, Centro-Oeste e Norte. Não houve TCC que tratasse cidades ou Estados da região sul do país. Entre as cidades estu- 
dadas nos TCC destaque para as cidades da Região Metropolitana da Grande Vitória, no Estado do Espírito Santo, sede do MPCR-UNIDA. Foram cinco na capital Vitória, quatro em Vila Velha, dois em Cariacica e três na Serra, totalizando 14 das 25 cidades pesquisadas (56\%). Além dessas, outras três cidades no interior do Estado ( $12 \%$ das cidades pesquisadas) foram foco de pesquisas, como Aracruz, Colatina e Santa Teresa. Destaque também para estudos em terras indígenas, como Sahu-Apé-AM e Uru Eu Wau Wau-RO, além da pesquisa em Aracruz-ES, que foi na terra indígena dos Tupiniquim e dos Guarani.

Figura 12 - Quanto aos Estados objetos de pesquisa nos TCC

\begin{tabular}{lcccc} 
Pesquisas nos Estados & $\mathbf{N}^{\mathbf{0}}$ & $\begin{array}{c}\text { \% das } \\
\text { Estaduais }\end{array}$ & \% do total & Região \\
\hline Amapá & 1 & 7,1 & 0,7 & Norte \\
\hline Espírito Santo & 10 & 71,4 & 6,6 & Sudeste \\
\hline Mato Grosso do Sul & 1 & 7,1 & 0,7 & Centro-Oeste \\
\hline Minas Gerais & 1 & 7,1 & 0,7 & Sudeste \\
\hline Pará TOTAL & 1 & 7,1 & 0,7 & Norte \\
\hline \multicolumn{1}{c}{ TOTan } & $\mathbf{1 4}$ & $\mathbf{1 0 0}$ & $\mathbf{9 , 3}$ & $\mathbf{3}$ \\
\hline
\end{tabular}

Fonte: Dados organizados pelos autores a partir dos títulos, palavras-chave e resumos dos TCC.

Cinco Estados da federação foram objeto direto de pesquisas nos TCC, situados em regiões diferentes do país, sendo a maioria das pesquisas concentradas no Estado do Espírito Santo (71,4\%). Combinando os dados da Figura 12 com os 11 Estados nos quais houve cidades que foram pesquisadas com a Figura 12, observa-se o incremento de outro Estado, o de Mato Grosso do Sul. Assim, os TCC abordaram 12 Estados brasileiros distribuídos em quatro das cinco regiões do país.

\section{Considerações finais}

O MPCR-UNIDA é ainda, em 2017, o único MP em Ciências das Religiões no país, pese sua autorização ter sido há sete anos. Se considerada a área de conhecimento Teologia e Ciência da Religião, há outros dois programas de pós-graduação stricto sensu MP, só que em Teologia (Faculdades EST e Faculdade Batista do Paraná, ambos no sul do país). O crescente número de matriculados (totalizando 336 em 2016) observado na taxa média de crescimento anual de $15,76 \%$ indica que a proposta pedagógica do curso está atendendo à demanda reprimida no país. O tema mais abordado foi a interface 
O trabalho de Conclusão de Curso (TCC) no Mestrado Profissional (MP): um estudo de 209 caso do MP em Ciências das Religiões da Faculdade Unida (UNIDA)

da Religião com a Educação, precisamente o Ensino Religioso, com pouco mais de um terço das pesquisas, 51 TCC de um total de 151 especialmente tratando o Ensino Religioso e outros 4 TCC versando aspectos específicos da Educação, como currículo e metodologia na interface com o ensino de outras disciplinas relacionadas com o fenômeno religioso. Nesse sentido, esse MP analisado contribuiu diretamente para a política da CAPES de incentivar a interface com a Educação no país. O segundo tema mais abordado foi a interface da Religião com o Direito, com 19 pesquisas acerca de alguns aspectos específicos da legislação brasileira. Se forem consideradas as discussões igualmente jurídicas sobre o Estado laico e a questão da liberdade religiosa, que ocupou outras 12 pesquisas, essa abordagem interdisciplinar da Religião com o Direito ocupou 20,5\% dos TCC no período 2011-2016. Outro tema recorrente foi a respeito do fenômeno do pentecostalismo e neopentecostalismo, com 10,6\% da produção, somando 16 TCC de 151 no período, que dialogaram especialmente com as subáreas Sociologia da Religião, Economia e Comunicação Social, confirmando o caráter interdisciplinar dos MPs.

Outra questão importante a ser destacada neste MP é sobre a regionalidade. Embora muitas das pesquisas tratem aspectos nacionais $(63 \%$ dos TCC), 25\% da produção total ocupou-se com cidades específicas (38 TCC), analisando objetos de estudo em 25 cidades do país, distribuídas em mais de 10 Estados e em quatro das cinco regiões do país. A ausência de TCC que trate da região sul do país pode ser entendida como consequência do fato de que nessa região existe a oferta de dois MPs em Teologia. Nas demais regiões, diversos fenômenos e situações concretas foram objeto de estudo. Destaque para três TCC em terras indígenas (dois no Norte e um no Sudeste do país) e para o fato de ter pesquisas em quatro das oito áreas do conhecimento (Ciências Humanas, Ciências Sociais, Ciências da Saúde e Linguística, Letras e Artes).

Como nota propositiva, seria importante que o referido MP incentivasse a criação de Grupos de Pesquisa que fizessem interface com essas outras áreas do saber que não foram objeto de pesquisa e aplicação, como as Artes, as Ciências Agrárias, as Engenharias, as Ciências Biológicas e as Ciências Exatas e da Terra. A diversidade de profissionais envolvidos com essas áreas e que poderiam fazer a interface com o fenômeno religioso representaria uma ampliação do atual público-alvo. 


\section{Referências}

CAPES. Plataforma Sucupira. Dados Quantitativos de Programas Recomendados e Reconhecidos. Disponível em: https://sucupira.capes.gov.br/sucupira/public/consultas/coleta/ programa/quantitativos / quantitativoAreaAvaliacao.jsf;jsessionid=kH114EBsFafs3KVgI2+xH P6R.sucupira-205. Acesso em: 7 abr. 2017.

CAPES. Portaria nº 47 de 17 de outubro de 1995. Revista Brasileira de Pós-Graduação, v. 2, n. 4, p. 147-148, jul. 2005.

ECO, Umberto. Como se faz uma tese. Trad. Gilson Cesar Cardoso de Souza. São Paulo: Perspectiva, 2005.

GUERRA, Yolanda. A polêmica sobre o mestrado profissional e a área de Serviço Social: Subsídios à reflexão. Boletín Electrónico Surá, Escuela de Trabajo Social - Universidad de Costa Rica, n. 200, mar. p. 1-15, 2013.

MATTOS, P. L. Dissertações não-acadêmicas em mestrados profissionais: isso é possível? RAC, v. 1, n. 2, p. 153-171, jan. 1997.

MEC. Portaria Normativa 17, de 28 de dezembro de 2009. Diário Oficial da União, n ${ }^{\circ}$. 248, terça-feira, 29 de dezembro de 2009. Disponível em: https://www.capes.gov.br/images/ stories/download/legislacao/PortariaNormativa_17MP.pdf. Acesso em: 8 abr. 2017.

MEC. Portaria nº 389, de 23 de março de 2017. Diário Oficial da União, n. 58, sexta-feira, 24 de março de 2017. Disponível em: http://www.capes.gov.br/images/stories/download/ legislacao/24032017-PORTARIA-No-389-DE-23-DE-MARCO-DE-2017.pdf. Acesso em: 9 abr. 2017.

MEC. PARECER HOMOLOGADO. Despacho do Ministro, publicado no D.O.U. de 30/9/2011, Seção 1, p. 43. Portaria nº 1.364, publicada no D.O.U. de 30/9/2011, Seção 1, p. 40. Acesso em: 11 nov. 2016.

MOREIRA, M. A.; NARDI, R. O mestrado profissional na área de ensino de ciências e matemática: alguns esclarecimentos. R.B.E.C.T., v. 2, n. 3, p. 8-15, set. 2009.

QUARESMA, A. G.; MACHADO, L. R. S. Questões pedagógicas dos mestrados profissionais: uma aproximação ao tema a partir de produções bibliográficas. Revista Brasileira de Pós-Graduação, v. 11, n. 24, p. 461-481, jun. 2014.

RIBEIRO, Renato Janine. O mestrado profissional na política atual da Capes. Revista Brasileira de Pós-Graduação, v. 2, n. 4, p. 8-15, jul. 2005.

SILVEIRA, V. O.; PINTO, F. C. S. Reflexões necessárias sobre o mestrado profissional. Revista Brasileira de Pós-Graduação, v. 2, n. 4, p. 38-47, jul. 2005.

UNIDA. Mestrado Profissional em Ciências das Religiões. Informações Gerais. Sitio web: www.faculdadeunida.com.br. Disponível em: http://www.faculdadeunida.com.br/site/cursos/ mestrado/informacoes-gerais. Acesso em: 8 abr. 2017.

Submetido em: 20-4-2017

Aceito em: 16-4-2018 